\title{
MULTIDISCIPLINARY IMAGING OF ROCK PROPERTIES IN CARBONATE RESERVOIRS FOR FLOW-UNIT TARGETING
}

\author{
SEMI-ANNUAL TECHNICAL REPORT
}

Reporting Period: 11/16/02 - 5/15/03

Author: Stephen C. Ruppel

Date Report Issued: July 2003

DOE Award Number: DE-FC26-01BC15351

Bureau of Economic Geology

Scott W. Tinker, Director

John A. and Katherine G. Jackson School of Geosciences

The University of Texas at Austin

Box X, University Station

Austin, TX 78713-8924 


\section{DISCLAIMER}

This report was prepared as an account of work sponsored by an agency of the United States Government. Neither the United States Government nor any agency thereof, nor any of their employees, makes any warranty, expressed or implied, or assumes any legal liability or responsibility for the accuracy, completeness, or usefulness of any information, apparatus, product, or process disclosed, or represents that its use would not infringe privately owned rights. Reference herein to any specific commercial product, process, or service by trade name, trademark, manufacturer, or otherwise does not necessarily constitute or imply its endorsement, recommendation, of factoring by the United States Government or any agency thereof. The view and opinions of authors expressed herein do not necessarily state or reflect those of the United States Government or any agency thereof. 


\begin{abstract}
Excellent progress continues to be made on most objectives and goals. Primary focus during the past 6 months has been (1) simulation of reservoir performance using the reservoir model constructed for the Phase 1 study area, (2) extension of core and log characterization activities to the Phase 2 study area, (3) development of an initial velocity-based inversion model from the 3-D seismic volume for porosity characterization, (4) continuation of quality-control analysis of wireline logs. Preliminary results of the study were presented at a technology-transfer workshop in May 2003 in Midland/Odessa Texas.
\end{abstract}




\section{Table of Contents}

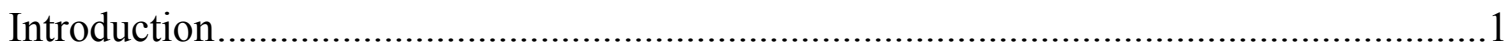

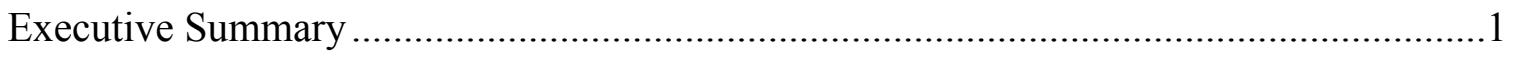

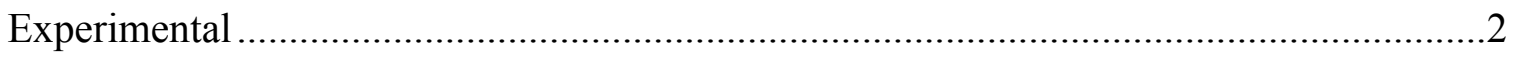

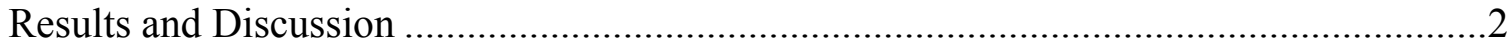

Subtask 1.1 Describe Facies and Cyclicity in Cores...................................................

Subtask 1.2 Describe Facies and Cyclicity in Outcrops ………………….................

Subtask 1.3 Develop Wireline Correlation Framework..............................................

Subtask 2.1 Measure Petrophysical Properties in Core ..............................................8

Subtask 2.2 Define and Characterize Rock Fabrics...................................................8

Subtask 2.3 Collect Relative-Permeability and Capillary-Pressure Data ...................9

Subtask 2.4 Calibrate Wireline Logs for Rock-Fabric Identification .........................10

Subtask 3.1 Collect Rock-Mechanics Data (Subcritical Crack Indices)....................11

Subtask 3.2 Model Fracture Growth ..........................................................................11

Subtask 4.1 Construct 3-D Seismic Attribute Model of Reservoir Porosity .............11

Subtask 4.2 Integrate 3-D Data with Rock-Fabric and Cycle-Stratigraphic Data ....14

Subtask 4.3 Distribute Reservoir Properties through Interwell Space.......................16

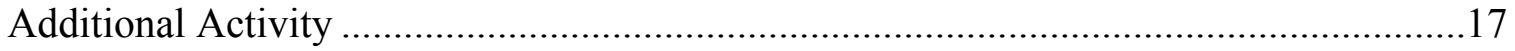

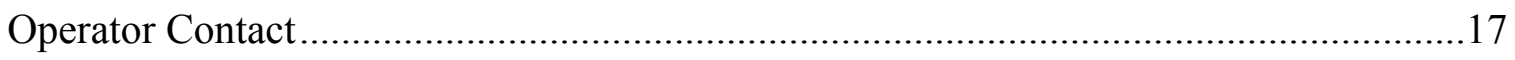

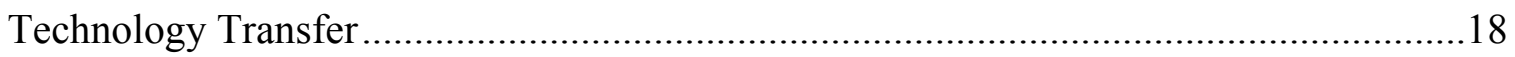

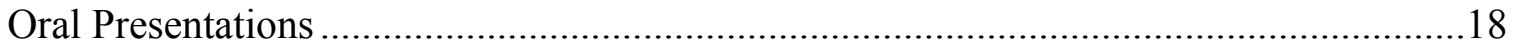

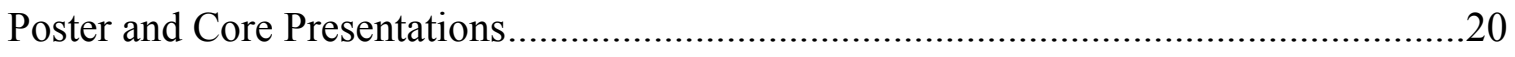

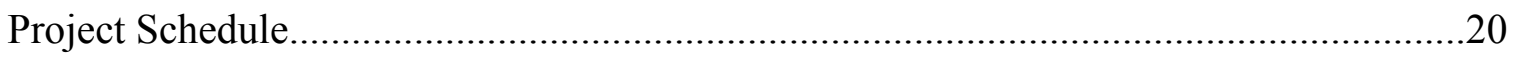

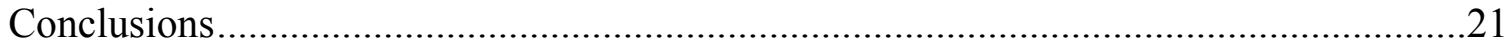

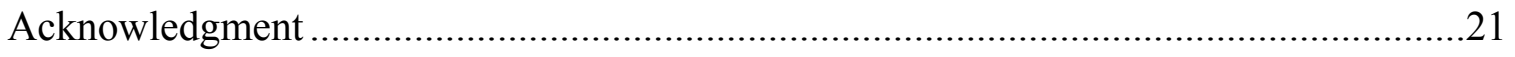

\section{Figures}

1. Regional map of the Permian Basin showing location of reservoir study and analogous outcrops 
2. Map of field showing location of study areas, cores, and 3-D seismic data..................4

3. Sequence stratigraphic model of the Clear Fork reservoir at Fullerton field..................7

4. Lower Clear Fork moldic-lime grainstone.............................................................

5. Distinction of interparticle and separate-vug porosity from wireline resistivity and

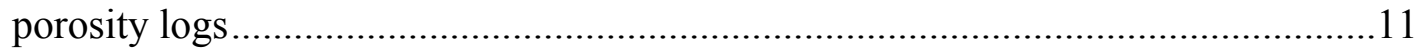

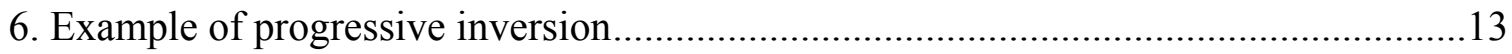

7. Plot showing relationship between calculated porosity and acoustic velocity in a Fullerton Clear Fork Unit well......................................................................... 15

8. Cross plot showing relationship between seismic velocity from 3-D data and calculated

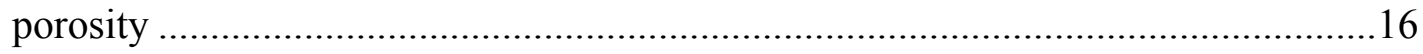




\section{Introduction}

We have made excellent progress toward most goals and objectives. The goals and objectives of the project remain essentially unchanged from the original proposal. This report describes the work accomplished on the project during months 13 through 18 of the project.

\section{LEONARDIAN OUTCROPS AND RESERVOIRS}

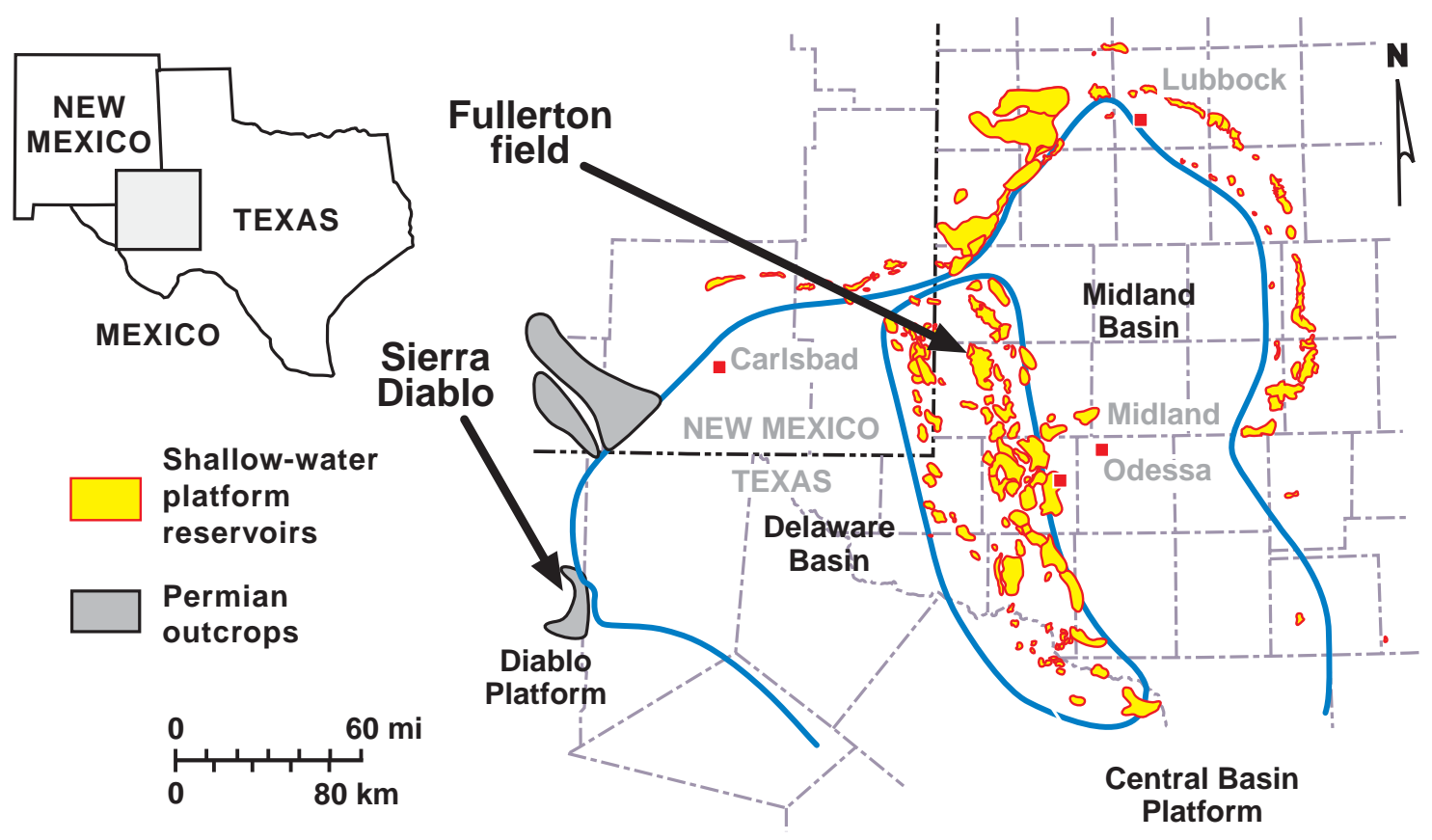

Figure 1. Regional map of the Permian Basin showing location of reservoir study and analogous outcrops.

\section{Executive Summary}

The project continued to make significant progress during the last 6 months. Major activities during the period were (1) expansion of core- and facies- based stratigraphic studies to the Phase 2 study area, (2) analysis of facies and sequence architectures in analogous outcrops in West Texas (fig. 1), (3) selection of samples 
for special core analysis, (4) construction of an inversion model to relate seismic velocity data to reservoir porosity, (5) continued quality checking of wireline-log data, and (6) completion of initial simulation runs for the Phase 1 reservoir model. Project delays are the result of delays in obtaining redigitized logs from the operator and the time necessary for checking and correcting errors found in the redigitized logs. It is likely that these log-handling-induced delays will cause a delay in the completion of the project. We plan to request a no-cost extension

\section{Experimental}

During the past 6 months, we selected 30 samples and submitted them for testing. All 30 samples were first scanned by the High-Resolution X-ray Computed Tomography Facility at The University of Texas at Austin to image their pore networks. Of these samples, 15 have now been submitted for electrical property and capillary-pressure measurements. The remaining 19 were submitted to a commercial core-analysis laboratory for capillary-pressure measurements. Results of the measurements will be used to (1) assess the impact of patchy occlusion of pore space by anhydrite on porosity-permeability relationships, (2) improve our capillary model for estimating original water saturation, and (3) evaluate our understanding of how moldic porosity impacts electrical properties.

\section{Results and Discussion}

During the last 6 months of the project, we have made substantial additional progress on most projects, tasks including Task 1, Construct Cycle Stratigraphic 
Framework, Task 2, Characterize and Model Rock Fabrics, and Task 4, Correlate and Model Rock Properties and 3-D Seismic Attributes.

Study of the Fullerton Clear Fork reservoir has been subdivided into three phases. The first two phases, Phase 1 and Phase 2, focus in turn on two small areas of the reservoir (locations of the Phase 1 and Phase 2 study areas shown in figure 2). Phase 3 will involve study of the remaining parts of the reservoir and an integration of all three areas. The first phase of the study is nearly completed. All Task 1 activities have been completed in the Phase 1 geographic area. Task 2 activities are continuing in the Phase 1 area. Task 1 efforts are now being conducted in the Phase 2 area and throughout the remainder of the project area. Task 4 activities are continuing throughout the field. 


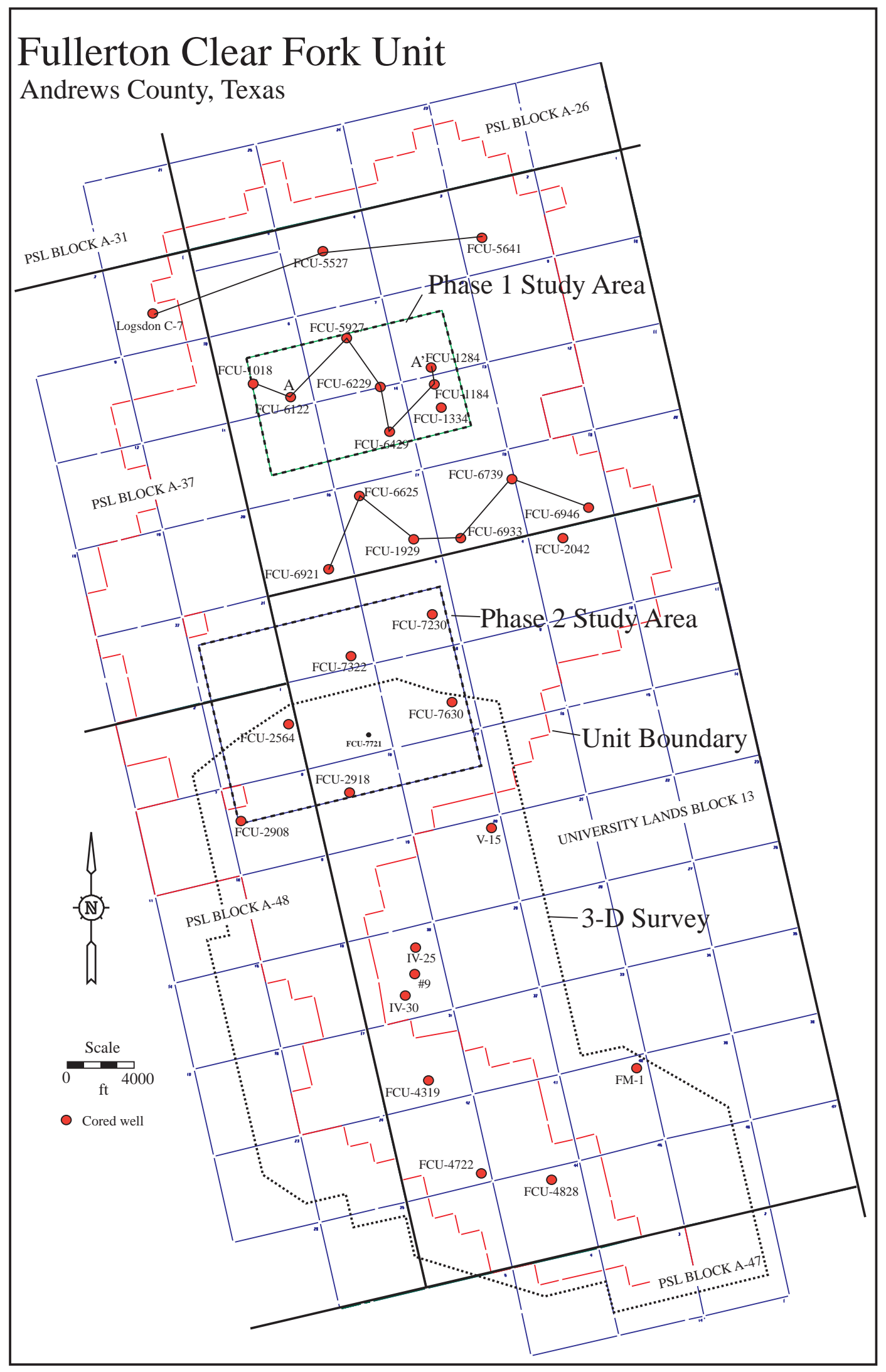


Figure 2. Map of field showing location of study areas, cores, and 3-D seismic data. Subtask 1.1 Describe Facies and Cyclicity in Cores.

Descriptions of cores in the field continue. All cores in the Phase 2 part of the study area have now been described, and two cores in the southern part of the field were also examined. In total, 4,208 feet of core was described. Five of these cores lie within the 3 -D seismic volume and are providing details facies/log/seismic ties that are critical to our efforts to build a tightly constrained seismic inversion model. Some of the cores are also being used to tie into 2-D seismic lines in the northern part of the field, where no 3-D data exist.

Most newly described cores show stratigraphic architecture and facies development similar to that documented for the Phase 1 study area. In all of these areas, the Lower Clear Fork is characterized by three high-frequency sequences, each composed of a basal leg of transgressive, tidal-flat-dominated facies; a subtidal middle leg (maximum flooding of the platform and early highstand), and a tidalflat-dominated upper leg (latest highstand). The underlying Wichita facies is typically dominated by tidal-flat deposits as in previously examined parts of the field. The southernmost of the recently described cores (Univ. Cons. IV-25), however, shows evidence of overall higher accommodation and more distal facies throughout the section. The Lower Clear Fork contains abundant fusulinid wackestones and packstones with cycle-capping peloidal packstones and graindominated packstones. The abundance of fusulinid-rich, mud-dominated cycle bases in the Lower Clear Fork documents a somewhat deeper water setting in this part of the field and has resulted in overall reservoir porosity and permeability that 
is lower than that observed in the central portion of the field. The greater accommodation and water depth developed in this part of the field is also apparent from the thinned Wichita facies succession and the underlying outer platform Abo clinoformal succession. The Abo, whose top is marked by thick karst dissolution, is characterized by low-porosity, anhydrite-cemented breccia fabrics. Facies are high in porosity and permeability but may lie below the oil-water contact.

On the basis of cores and analogous outcrop studies studied to date, we have developed a general model of sequence stratigraphic architecture of the reservoir succession at Fullerton field (fig. 3). Key elements depicted by the model are (1) the definition of three high-frequency sequences in the Lower Clear Fork succession, each of which contains transgressive and regressive legs; (2) the realization that the Wichita tidal-flat facies represent both the later highstand deposits of Leonardian sequence L1 and transgressive deposits of Leonardian sequence L 2; (3) the definition of karst-related dissolution features (cave-fill sediments and breccias and collapse features) at and below the L1/L2 sequence boundary; (4) the recognition that the Abo succession is highly porous and permeable and may be untapped in many parts of the field; and (5) the documentation of a subtidal basinward leg of HFS 2.3 on the east side of the field that contains good reservoir-quality facies and may not have been fully exploited. 


\section{SEQUENCE STRATIGRAPHIC MODEL Lower Clear Fork - Wichita - Abo: Fullerton Field}

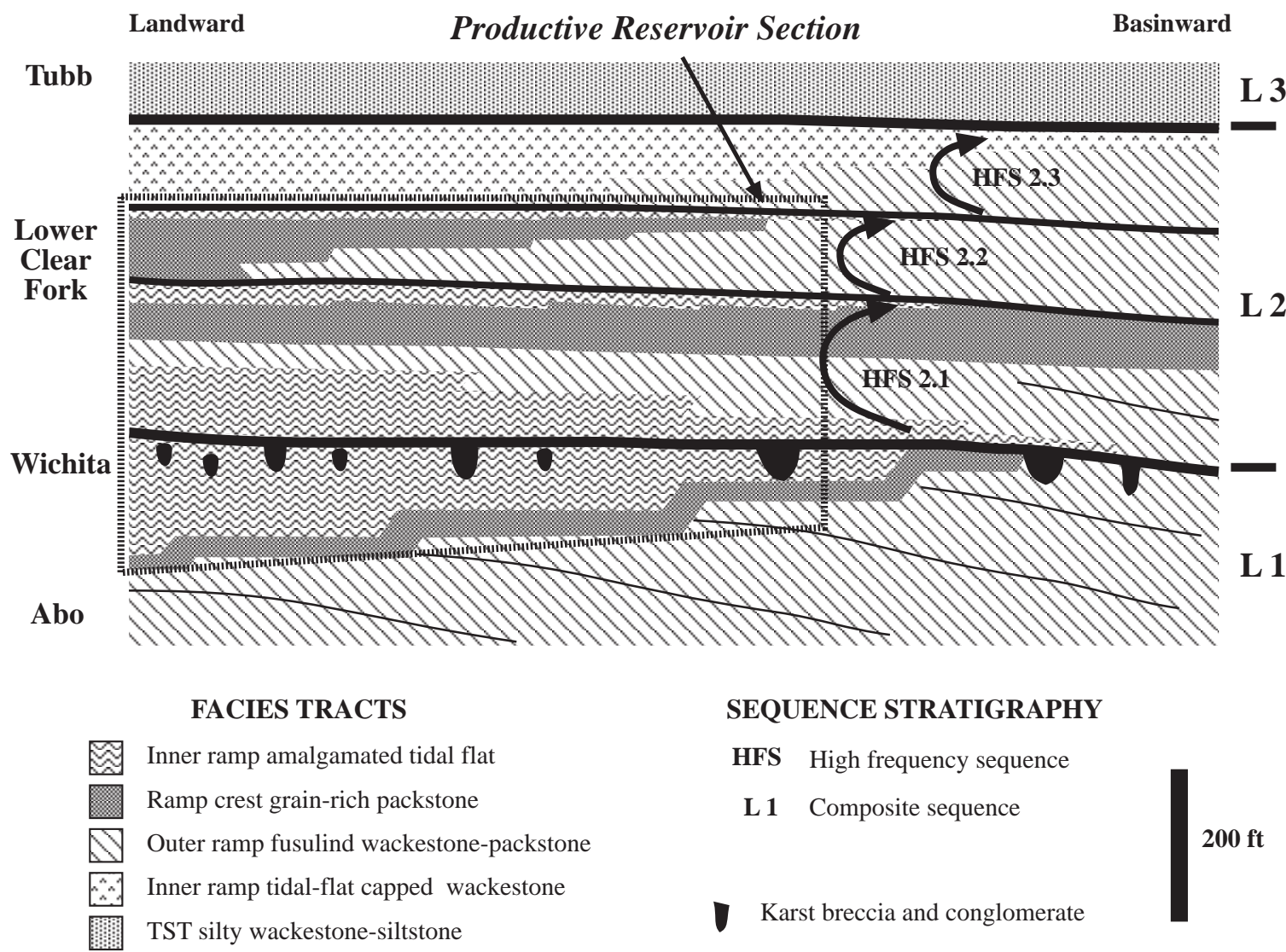

Figure 3. Sequence stratigraphic model of the Clear Fork reservoir at Fullerton field.

Subtask 1.2 Describe Facies and Cyclicity in Outcrops.

Outcrop characterization of rocks equivalent to the Lower Clear Fork and

Wichita reservoir succession at Fullerton field continued in outcrops of West Texas.

During December, we revisited the Sierra Diablo Mountains (fig. 1) to describe

facies successions and sequence architecture along the platform margin that may

help provide analogs for depositional styles encountered along the eastern, downdip margin of the Fullerton reservoir. 


\section{$\underline{\text { Subtask 1.3 Develop Wireline Correlation Framework. }}$}

We are continuing to expand our cycle-based log correlations of the reservoir succession across the field. Current emphasis is in the Phase 2 area. Subtask 2.1 Measure Petrophysical Properties in Core.

We have selected 30 samples for special core analysis. The 30 samples have been scanned by the UT High-Resolution X-Ray Computed Tomography Facility, and the results are being analyzed. We have submitted 15 samples for electricalproperty and capillary-pressure measurements. The remaining 19 are in the process of being submitted for capillary-pressure measurements. The results of these measurements will be used to assess the impact of patchy occlusion of pore space by anhydrite on porosity-permeability relationships, improve our capillary model for estimating original water saturation, and evaluate our understanding of how moldic porosity impacts electrical properties.

\section{Subtask 2.2 Define and Characterize Rock Fabrics.}

Approximately 200 new thin sections were selected and cut from cores in the Phase 1 area (FCU 6429, 6122, 6229) for thin-section preparation. These thin sections were then described to characterize reservoir rock-fabric types. We selected these thin sections to gain additional data about the uppermost portion of the Lower Clear Fork reservoir because previously described thin sections did not adequately sample this part of the reservoir. In particular, we sampled the FCU 6122 to gain a better understanding of a distinct interval of moldic limestone present in one part of the study area. Rock-fabric types observed in these thin sections include class 1 grain-dominated, coarse-crystalline dolostones and moldic 
lime grainstones (fig. 4) and class 2 grain-dominated, medium-crystalline dolostones and moldic-lime, grain-dominated packstones.

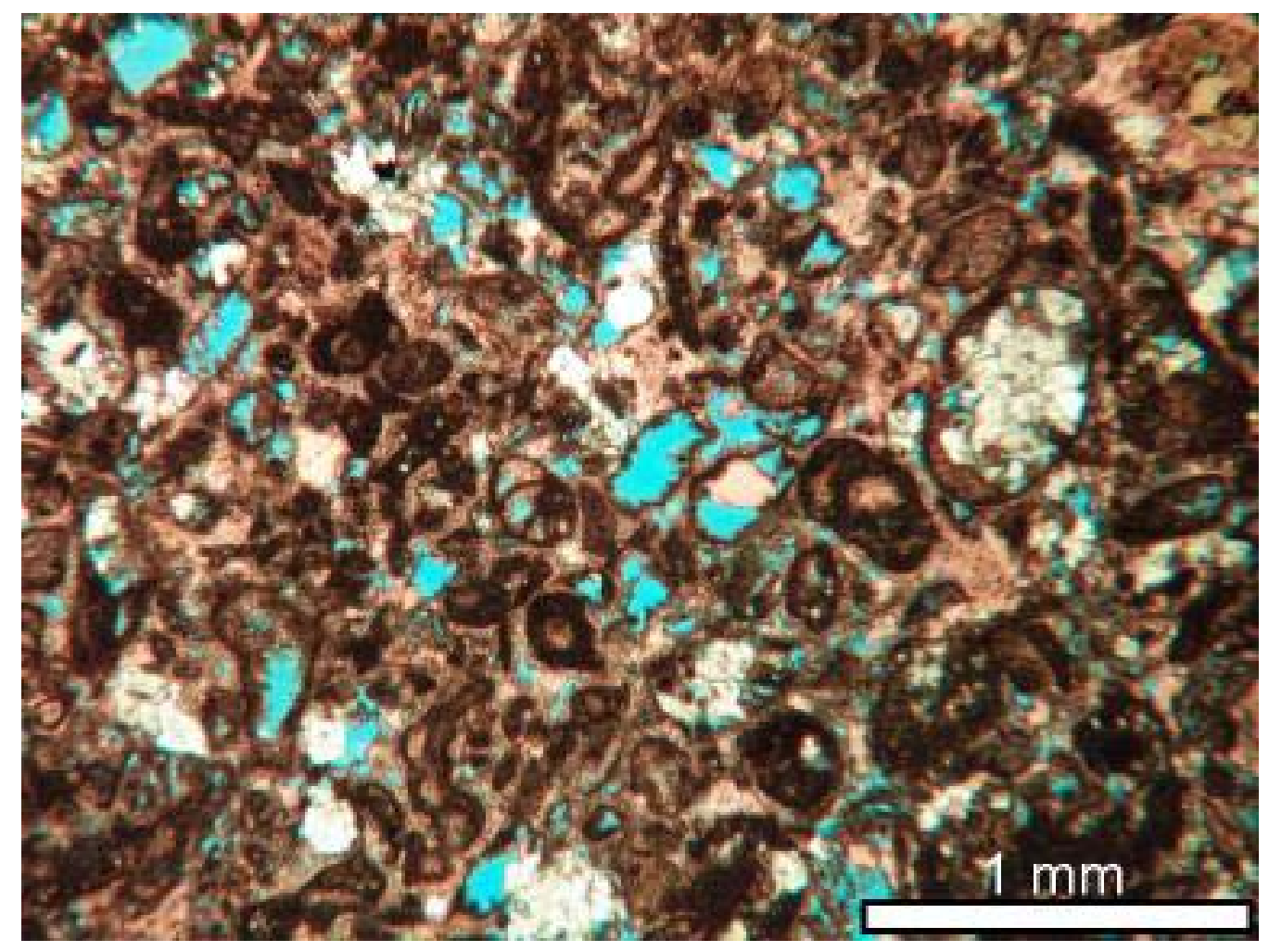

Figure 4. Photomicrograph of Lower Clear Fork moldic-lime grainstone.

In addition, we described all existing thin sections available from three cores in the Phase 2 area (FCU 7630, 7230, 7322). These 164 thin sections display a range of class 2 and 3 rock fabrics similar to those observed in the Phase 1 study area. Similarly, class 2 samples plotting in the class 1 region may be explained by the presence of poikilotopic anhydrite. However, existing whole core analysis from these wells is a poor match to some of these thin sections, so new core analysis with matching thin sections may be required. 


\section{Subtask 2.3 Collect Relative-Permeability and Capillary-Pressure Data.}

Thirty-four carefully selected core plugs have been collected and submitted for capillary-pressure measurements. Measurements of relative permeability are being delayed until further reservoir characterization is completed.

\section{Subtask 2.4 Calibrate Wireline Logs for Rock-Fabric Identification.}

Continued progress has been made in using wireline-log suites to define rock-fabric types. Quantitative relationships have been developed to tie basic porosity-log data to rock-fabric type in stratigraphically correlatable units. Additional research suggests that porosity, derived directly from resistivity logs, when compared with traditional total porosity logs, can provide additional information with regard to rock fabrics. Because the dominant modern wireline-log suite in the field consists of a resistivity-log suite and a single total-porosity log, this avenue has become a major line of investigation. Figure 5 illustrates the potential of this method. In this case, interparticle porosity is calculated strictly from the resistivity logs (red hatching in the center track, fig. 5). Separate-vug porosity (blue hatching in the in the center track) is calculated by subtracting the resistivitycalculated porosity from total porosity calculated from traditional porosity logs. Comparison of point-counted separate-vug porosity (magenta points in right track) and log-derived separate-vug porosity (blue curve in right track) shows that the agreement is quite good. The two lithology columns to the far left show the logderived lithology and core lithology from description, also showing good agreement. 

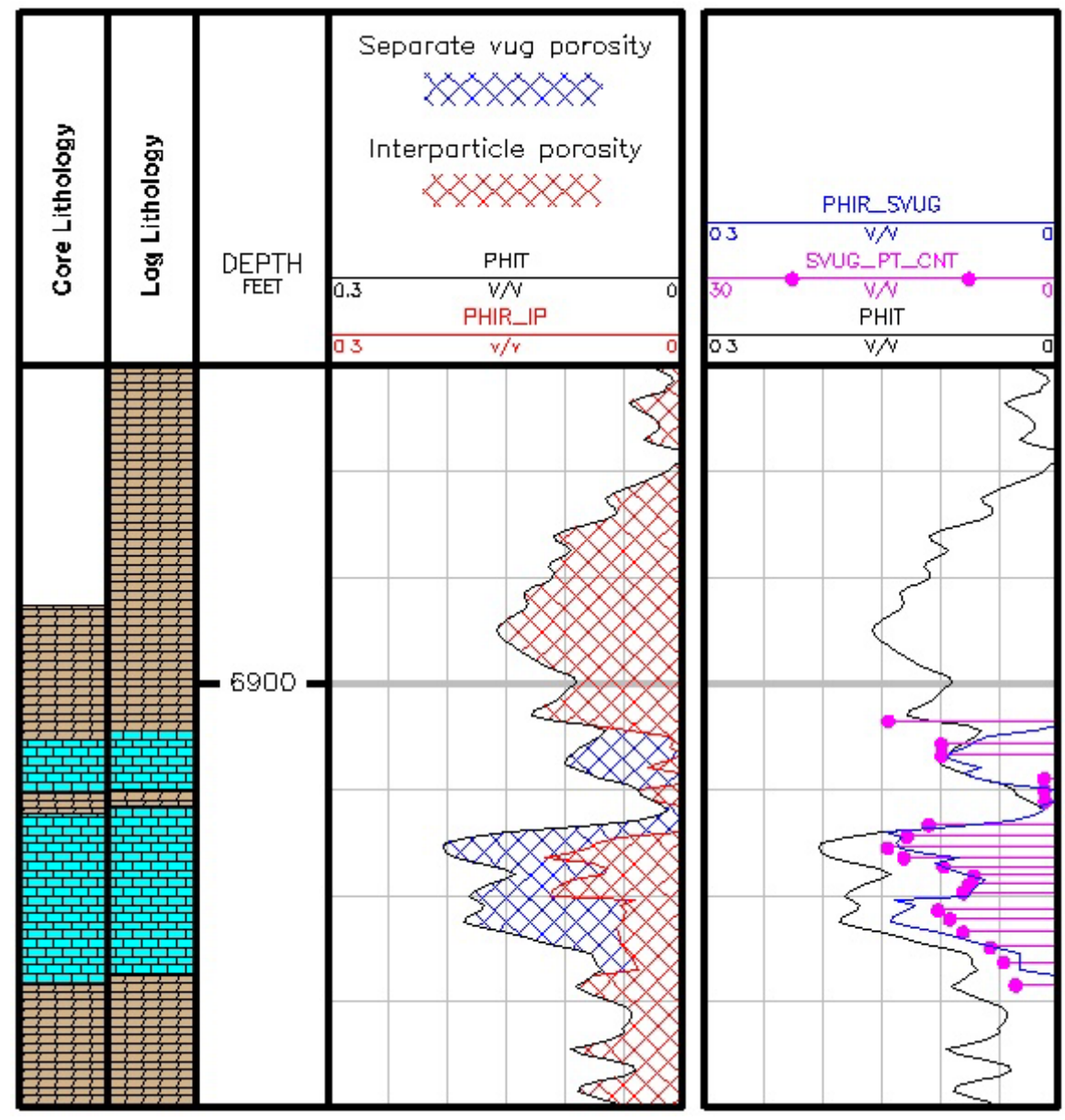

Figure 5. Distinction of interparticle and separate vug porosity from wireline resistivity and porosity logs.

\section{Subtask 3.1. Collect Rock-Mechanics Data (Subcritical Crack Indices).}

This task has been deferred until rock fabrics are more accurately understood.

Subtask 3.2. Model Fracture Growth.

No significant fractures have been observed to date.

Subtask 4.1 Construct 3-D Seismic Attribute Model of Reservoir Porosity.

We continued to work on seismic attribute analysis and inversion of 3-D seismic data. The purpose is to integrate high-resolution stratigraphic information 
from well $\log$ and core interpretations to seismic inversion for improved 3-D mapping of the reservoir. We tested an unusual inversion approach, progressive inversion, by using the Hampson-Russell model-based inversion-package assistant with user-coded Fortran programs. We accomplished several tasks: (1) we selected more than 50 usable porosity logs and input them into the Hampson-Russell platform with individually calculated time-to-depth relationships, (2) we calculated a pseudo-impedance log for each well using a generalized porosity-to-impedance transform, (3) we extracted a wavelet from 3-D seismic data, (4) we made synthetic seismograms for each well for a correct well-seismic tie, (5) we built an initial impedance model by using well logs and seismic horizons following geologic boundaries interpreted from cores and logs, and (6) we ran a model-based seismic inversion. From the first inverted impedance volume, the interpretation of available seismic horizons can be improved and more control horizons can be picked. This approach will be used for building the next initial impedance model. Procedures 5 and 6 will be repeated until the inversion is satisfactory. Figure 6 shows how this process can combine high-resolution well log data with low-resolution seismic data for better reservoir imaging. Although very fine scale cycles are apparent on well porosity logs, seismic data allow us to pick only $100 \mathrm{ft}$ or thicker high-frequency sequences (fig. 6a). After the third round of inversion modeling, however, we can easily define layers as thin as $20 \mathrm{ft}$ (fig. 6b). 
a.

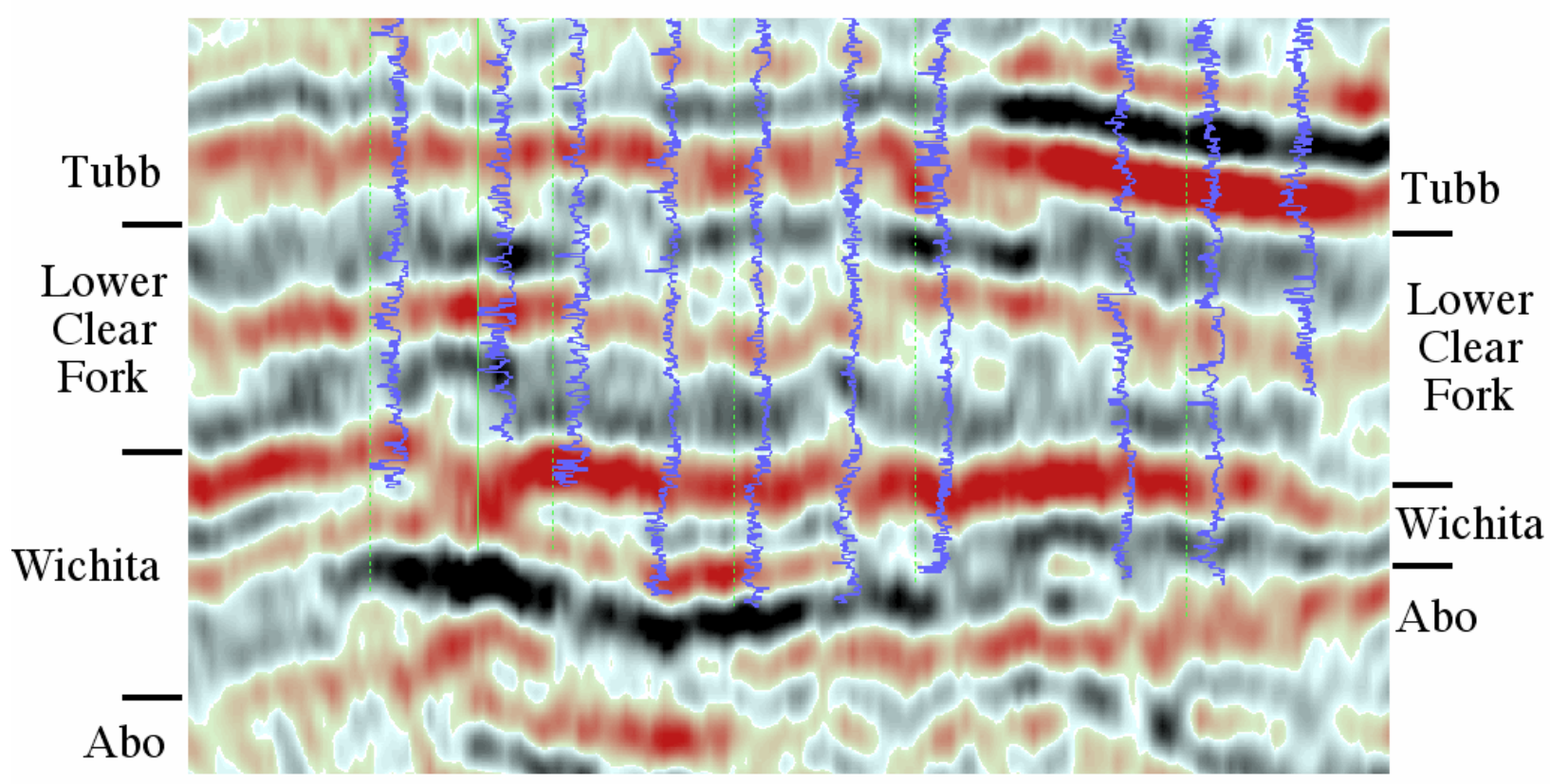

b.

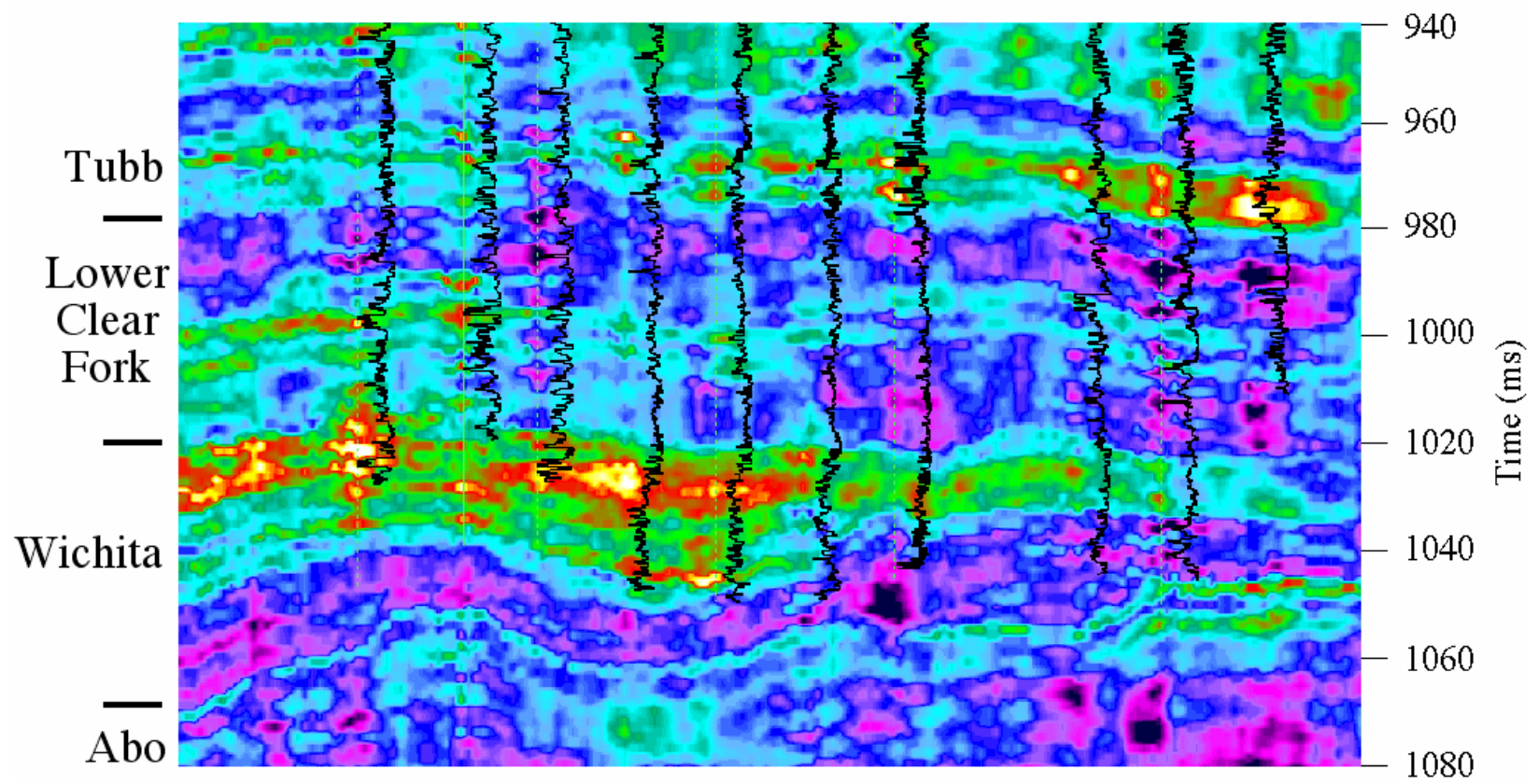

Figure 6. An example of progressive inversion. a. Seismic section tied to well porosity logs. b. Seismic inversion result. 
A substantial effort has also been directed at reprocessing 2-D seismic lines recently made available by ExxonMobil. These lines were acquired in different surveys at different times and are quite different in characteristics. If displayed in the initial form they are very difficult to be tied to one another or to available 3-D volumes. Accordingly we have followed a three-step procedure performed on a line-by-line basis using the Landmark Poststack tool to reprocess them: (1) correct the seismic phase $\left(150^{\circ}\right)$ to $90^{\circ}$ for better stratigraphic and lithologic interpretation, (2) apply a constant time shift (300-500 ms) to match 3-D volumes and other 2-D lines in traveltime, and (3) perform spectral balancing to enhance high-frequency components in the data. We now have a total of 30 2-D seismic lines distributed between and within the 3-D seismic volumes. Initial analysis shows that these 2-D lines provide valuable additional information for structure, stratigraphy, and reservoir architecture in the area.

Subtask 4.2. Integrate 3-D Data with Rock-Fabric and Cycle-Stratigraphic Data.

This task has begun with an examination of the relationship between acoustic velocity and porosity. In the study area, in all wells with both sonic and calculated porosity logs, we observed good statistical correlation between the two (fig. 7). For example, in well FCU 2723 in the Phase 2 area, high-porosity, grainrich, peloid-ooid packstones in the Lower Clear Fork are characterized by lower velocities. On the other hand, low-porosity, fusulinid-peloid, wackestones/packstones exhibit higher velocities. A cross plot of porosity and velocity reveals a linear relationship between the two, with a correlation coefficient of 0.85 (fig. 8). This relationship will allow us to link seismic attributes to porosity 
and then, hopefully, eventually to rock-fabric facies. We have already observed that seismic amplitude is a good indicator of porosity in some thicker units (e.g., highfrequency sequences L 2.1 and L 2.2). More detailed integration will be done to increase the resolution of porosity zones to the cycle scale with high-resolution inversion data. 


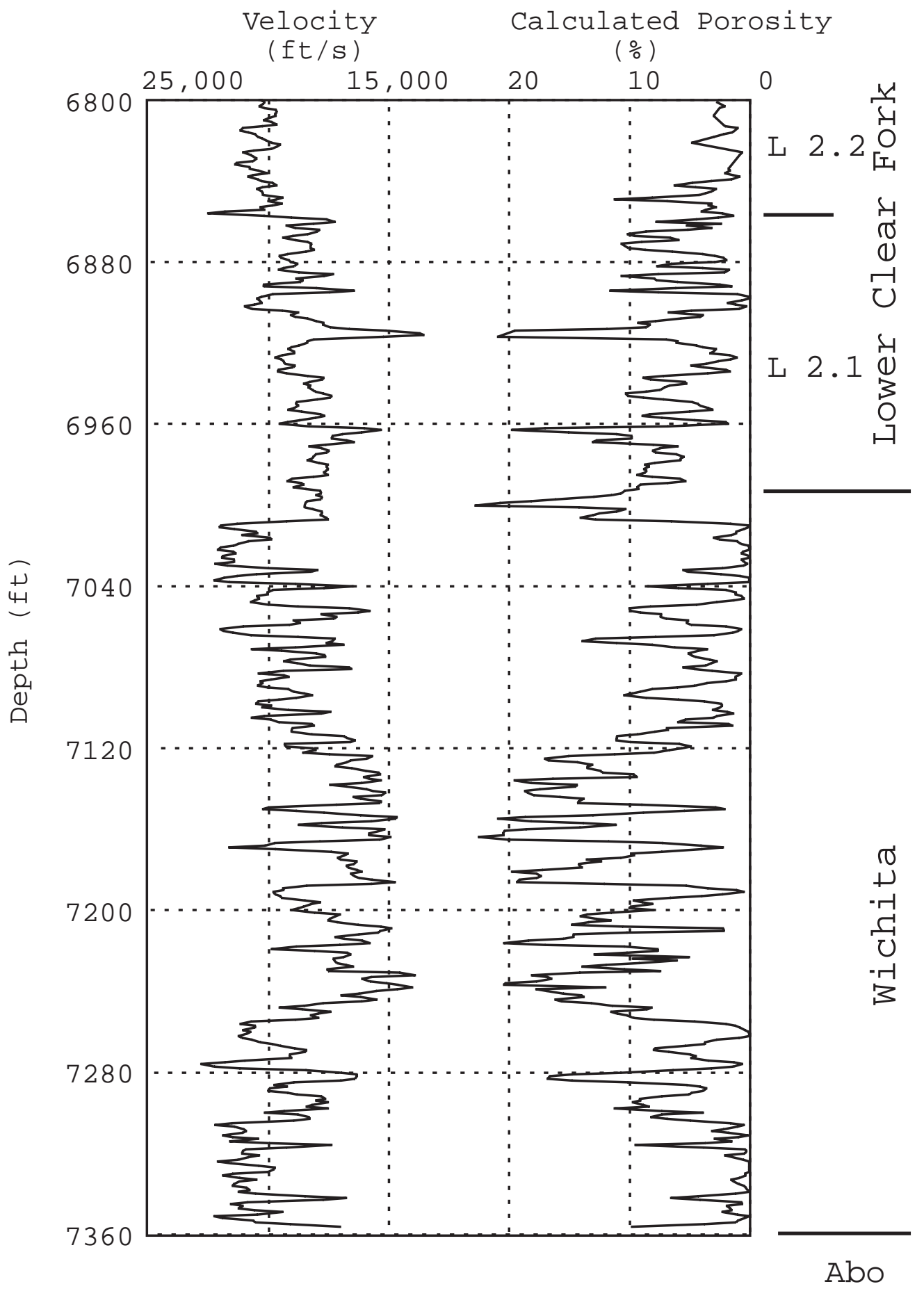

Figure 7. Plot showing relationship between calculated porosity and acoustic velocity in a Fullerton Clear Fork Unit well. 


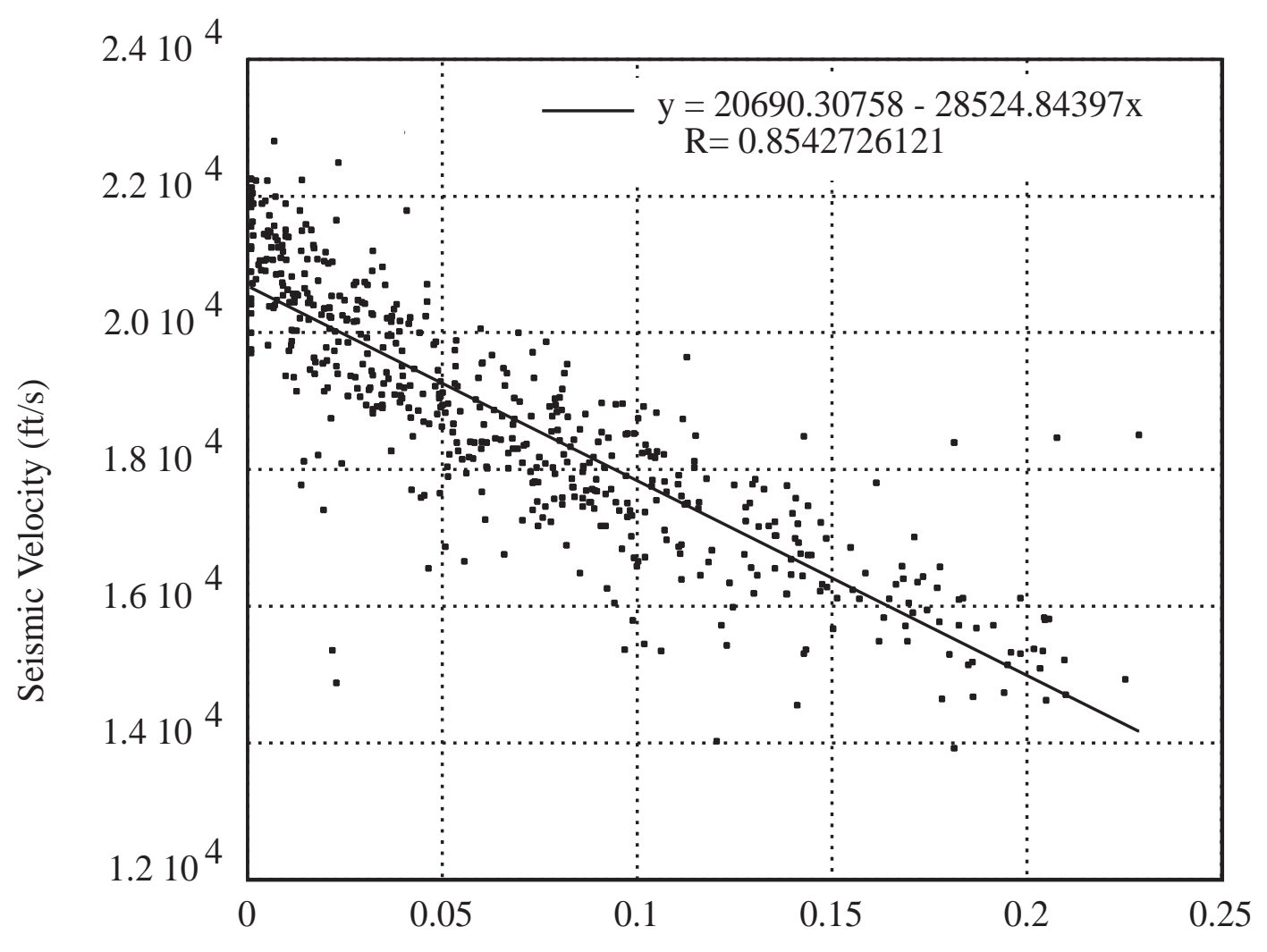

Calculated Log Porosity

Figure 8. Cross plot showing relationship between seismic velocity from 3-D data and calculated porosity.

\section{Subtask 4.3. Distribute Reservoir Properties through Interwell Space.}

Using wireline logs, we correlated 39 rock-fabric flow layers within highfrequency cycles in cores. These flow layers help define the geologic framework for 3-D modeling. A fine-scale geological model containing 3.2 million cells $(140 \times 90 \times 256)$ was constructed first using RMS from ROXAR Inc., and porosity, permeability, and water saturation were mapped through the 3-D space. The geological model was then scaled up to a coarse reservoir model containing 130,000 cells $(73 \times 48 \times 39)$ for reservoir simulation. 
The simulation study has been divided into three phases: sensitivity study, history matching, and performance prediction. From the sensitivity study we can rank the importance of reservoir parameters affecting production performance. Through history matching, optimal fluid and rock properties can be determined. In the prediction phase, a variety of recovery technologies for maximizing oil recovery can be studied.

\section{Additional Activity}

Basic log-quality control has become a major issue because the logs have been digitized coincidently with the study. Therefore, prior to receiving the data, nothing more than cursory review of the digitization has been done. Significant problems were noted early on and have resulted in a number of logs being redigitized. Virtually all of the wireline logs have been digitized, although at this time fewer than half have been quality checked. The rate is improving as the people involved become more familiar with specifics of digitization. Given the current rate of throughput, completion is expected to be on schedule with the other aspects of the project.

\section{Operator Contact}

Bureau of Economic Geology project staff met with David Smith and Terry Anthony (ExxonMobil geologist and engineer, respectively) in Austin to discuss project progress. Bureau staff present included Steve Ruppel, Rebecca Jones, Jeff Kane, Hongliu Zeng, Fred Wang, Jerry Lucia, and Eric Potter. Tim Hunt attended from the UT system Midland WTO office. Agenda items included (1) reviews of Phase 1 porosity-modeling activities, rock-fabric studies, permeability modeling, 
flow-unit definition and (2) in-depth discussions of Phase 1 reservoir modeling and simulation work, as well as the saturation state of the Abo. A key item on the agenda was a discussion of the Phase 1 reservoir model and early efforts to start a simulation of the model. Terry Anthony provided important data on production and injection histories of wells in the model. The Bureau will provide a copy of the reservoir model to ExxonMobil so Terry can begin to examine the model parameters in more detail. An overview of the rock-fabric work and vertical distribution of petrophysical parameters that were used to characterize flow layers in the Phase 1 study area model was also presented

ExxonMobil has asked the Bureau to recommend well locations for infill drilling on the west flank of the field. This is an area of relatively low oil production and poor data quality; the logs are old, uncalibrated gamma-ray neutron logs, and no cores exist in the area. Key to the analysis of this area is the 3-D seismic data that the Bureau is analyzing as part of the project. We will utilize our interpretation of the seismic data to define the structural setting of the proposed infill area and the distribution of porosity on the basis of seismic-attribute analysis. We will then provide ExxonMobil with an interpretation of which localities would be best to consider for infill.

\section{Technology Transfer}

A workshop has been scheduled to present preliminary findings of the study. The title of the workshop will be "New Methods for Locating and Recovering Remaining Hydrocarbons in the Permian Basin." The workshop, which will be co-sponsored by the Bureau, PTTC, and the University Lands Office, will be held at the CEED center in 
Midland/Odessa. The planned agenda follows. Presentations based on the Fullerton project study are listed in bold type.

\section{Oral Presentations}

"Overview of Bureau of Economic Geology research in the Permian Basin":

Eric Potter, Associate Director for Energy, Bureau of Economic

$\underline{\text { Geology }}$

“Overview of University Lands West Texas Operations":

F. Stephen Hartmann, Executive Director of University Lands

"Overview of PTTC Programs in the Permian Basin":

Bob Kiker, PTTC Texas Region Permian Basin Director

"Oil and gas resource assessment of University Lands, Permian Basin, West Texas": Eugene M. Kim and Stephen C. Ruppel

"Predicting and characterizing fractures in the Ellenburger: using the link between diagenesis and fracturing”: $\underline{\text { Julia F. W. Gale }}$

"Pore networks in Lower Ordovician Ellenburger Group collapsed paleocave systems: examples from Barnhart field, Reagan County, Texas":

Robert A. Loucks and Deanna Combs

"Controls on the distribution and development of porosity and permeability in Clear Fork reservoirs in the Permian Basin": Stephen C. Ruppel 
"Reconditioning seismic data to improve carbonate stratigraphic interpretation and reservoir characterization, Clear Fork Group, Fullerton field, West Texas": Hongliu Zeng

"Better than a porosity cutoff: the rock-fabric approach to understanding porosity and permeability in the Lower Clear Fork and Wichita, Fullerton field": Rebecca Jones and F. Jerry Lucia

"Estimation of interparticle/intercrystalline porosity from resistivity logs": Jeff Kane

"Defining flow layers in the Lower Clear Fork and Wichita-Albany reservoir of Fullerton field": F. Jerry Lucia

"Regional Yates gas resource assessment and reservoir characterization, Permian Basin, Texas": Eugene M. Kim

\section{Poster and Core Presentations}

"Ellenburger Group collapsed paleocave facies, Barnhart field, Texas": Deanna Combs, Robert A. Loucks, and Stephen C. Ruppel

"Play analysis of major oil reservoirs in the Permian Basin, West Texas": Shirley P. Dutton, Eugene M. Kim, and Mark H. Holtz

"New techniques in fracture imaging and quantification: applications in the Ellenburger Group, West Texas": Leonel Gomez and Julia F. W. Gale 
"Regional Yates gas resource assessment and reservoir characterization, Permian Basin, Texas": Eugene Kim, Susan Hovorka, and Deanna Combs

"Oil and gas resource assessment of University Lands, Permian Basin, West Texas": Eugene M. Kim and Stephen C. Ruppel

"Vertical distribution of permeability and petrophysical class within the Lower Clear Fork and Wichita: inputs for reservoir modeling at Fullerton field": F. Jerry Lucia and Rebecca Jones

"Clear Fork reservoir architecture and controls on reservoir development: models from outcrop and subsurface data": Stephen Ruppel

"3-D modeling of Clear Fork reservoirs: Fullerton field": Fred Wang

\section{Project Schedule}

Although considerable progress has been made, the overall project is behind schedule. This delay stems from two causes. First, although the original plan was to have the reservoir characterization project well under way before the DOE phase of the project began, approval from the operator, ExxonMobil, was not granted until January 2002, more than 6 months after the originally planned start date in the spring of 2001. The DOE phase of the project was funded and started in November 2001, before agreement was received from the operator for the project start. Thus, at the time of DOE-funding startup, the project was approximately 6 months behind the original schedule. The second cause has been the long delays in receiving quality digital logs from the operator. Although all logs have now been redigitized 
and delivered to the Bureau, delays in receiving the logs and checking them for errors have taken a lot of unexpected staff time and have further delayed the project. For these reasons, we anticipate the need to ask for a no-cost extension to the project. This request will be submitted to DOE during the summer.

\section{Conclusions}

Good progress was made on the project in several areas during the past 6 months. Major activities included (1) continued work on perfecting the simulation of fluid flow in the Phase 1 area reservoir model, (2) extending of core- and log-based stratigraphic architecture to the Phase 2 area of the field, (3) development of preliminary inversion models for predicting porosity from 3-D seismic velocity, (4) continuing of quality assessment of new digital wireline logs, and (5) planning of technology-transfer workshop. Because some of the activities proposed in the original proposal have been delayed because of the late project start and delays in obtaining and correcting wireline logs, we plan to request a no-cost extension of the study.

\section{Acknowledgment}

We acknowledge the support of this project by Landmark Graphics Corporation via the Landmark University Grant Program. 